\title{
Tramas de religiosidade na ficção: a teledramaturgia e seus cruzamentos de sentidos,
}

\author{
Emilson Ferreira Garcia Junior ${ }^{1}$ \\ Robéria Nádia Araújo Nascimento ${ }^{2}$
}

\begin{abstract}
Resumo: Este estudo buscou compreender os sentidos religiosos abordados pela teledramaturgia da Rede Globo, a partir da análise das obras ficcionais Amor Eterno Amor, A Viagem e Escrito nas Estrelas, livremente inspiradas na doutrina espírita de Allan Kardec. Para a verificação desse cenário, o estudo envolveu dois procedimentos metodológicos: primeiro, a análise de narrativas, e num segundo momento, entrevistas com especialistas religiosos, além de questionários com os estudantes do curso de Comunicação Social. Diante desse contexto, pensar o papel da teledramaturgia no enfoque de novas práticas de religiosidade mostra-se uma perspectiva de investigação relevante para o campo da comunicação, considerandose que a ressonância e os impactos da ficção televisiva não terminam no último capítulo.

Palavras-chave: teledramaturgia; religiosidade; ficção. midiatização; contexto.
\end{abstract}

\begin{abstract}
This study sought to understand the religious meanings covered by Rede Globo soap operas, from the analysis of fictional works Love Eternal Love, The Voyage and Written in the Stars, freely inspired by the spiritual doctrine of Allan Kardec. To check this scenario, the study involved two methodological procedures: first, the analysis of narratives, and a second phase, interviews with religious experts, and questionnaires with students of Social Communication. In this context, to reflect upon soap operas role focusing on new religiosity practices is a relevant perspective to the field of communication research, considering that the resonance and impact of television fiction does not end on the last chapter.
\end{abstract}

Keywords: tv drama; religion; fiction; media coverage; context.

\section{Introdução}

Hoje, a mídia televisiva exerce papel de confluência com diversas denominações doutrinárias, popularizando diferentes crenças e originando, com isso, uma nova "indústria cultural” de matriz religiosa. Esse cenário alcançou a

\footnotetext{
${ }^{1}$ Mestrando em Ciência da Informação da Universidade Federal da Paraíba (UFPB). Email: emilson.uepb@gmail.com

2 Doutora em Educação pela Universidade Federal da Paraíba (2007). Professora Titular do curso de Comunicação Social (UEPB).E-mail: rnadia@terra.com.br
} 
teledramaturgia brasileira, despertando a nossa atenção para o cruzamento de sentidos entre mídia e religiosidade, especialmente nos espaços das narrativas ficcionais da Rede Globo. Assim, para identificarmos esses aspectos, adotamos como eixos de análise as telenovelas Amor Eterno Amor (escrita por Elizabeth Jhin), A Viagem (de Ivani Ribeiro, exibida pela primeira vez em 1994 e reprisada três vezes no Vale a Pena Ver de Novo - última exibição em 2006) e Escrito nas Estrelas (também de autoria de Elizabeth Jhin, exibida em 2010), inspiradas na doutrina espírita de Allan Kardec.

Estas são entendidas aqui como instâncias narrativas e interativas de produção, circulação e geração de múltiplos sentidos. Nesses termos, convém salientar que a visibilidade da ficção independe de temporalidade das exibições, uma vez que as tramas se mantêm vivas no imaginário do público em razão das mensagens que evocam. "A narrativa não se exaure, conserva-se com poder de coesão, trazendo possibilidades de desdobramentos futuros" (MOUSINHO, 2012, p. 161). As três novelas apontam fruição estética, empatia popular e significativa aceitação dos enredos. A esse respeito, Paiva (2010) salienta que o gênero telenovela alimenta a curiosidade pelo sobrenatural e pelas questões religiosas, ajudando a compor "o ethos místico-religioso do povo brasileiro, garantindo notoriedade ao espaço cotidiano da televisão" (PAIVA, 2010, p. 16).

\section{Percurso metodológico}

A teledramaturgia da Rede Globo apresenta uma significativa recorrência à temática religiosa e/ou seus desdobramentos. Assim, observamos como as narrativas das telenovelas mencionadas tratam esses enfoques a fim de avaliar seus possíveis efeitos de repercussão social, uma vez que a recepção está sempre atrelada às mediações dos sujeitos sendo construídas no ambiente da coletividade. A visão de Santaella (2001) corrobora nosso ponto de vista, pois, de acordo com a autora, as pesquisas que avaliam a interface entre a mensagem e a recepção conseguem verificar a eficácia comunicativa e persuasiva dos conteúdos midiáticos na sociedade.

Na produção ficcional, as narrativas possuem um eixo de articulação de histórias, em suas nuances secundárias ou essenciais, formatando um texto 
composto por integrações, interpenetrações de fatos e encaixes sucessivos realizados entre atores, enredo e imagens. Considerando que as novelas são obras lineares, seriadas e sistemáticas, estabelecemos um recorte narrativo, selecionando, a título de síntese, fragmentos capazes de ilustrar a investigação. Desse modo, pensar a recepção das telenovelas nas suas implicações contextuais impulsiona a verificação dos conceitos estudados nos entremeios em que ocorrem. Nesse raciocínio, definimos a realidade de Campina Grande para conhecermos as implicações dessas narrativas. Assim, o percurso metodológico ocorreu em dois momentos: o primeiro, destinado ao conhecimento dos enredos, a fim de sabermos o que dizem essas telenovelas; o segundo, direcionado às entrevistas com os especialistas em Espiritismo e à aplicação de questionários com os telespectadores, a fim de avaliarmos a percepção dos efeitos das tramas.

As entrevistas em profundidade e a aplicação de questionários são técnicas que, conforme Duarte (2005), obtêm respostas a partir da experiência subjetiva de uma fonte. A modalidade adotada neste estudo foi a entrevista semiaberta, que emerge de um roteiro-base, mas valoriza a dinâmica dialógica do processo de interlocução. Os especialistas do Espiritismo entrevistados foram: Ivanildo Araújo Fernandes, Professor Doutor da UFCG e Presidente da Associação Municipal de Espiritismo (AME); Oscar de Lira Carneiro, Professor Doutor da UFCG e Membro da Diretoria da SEJA (Sociedade Espírita Joana de Ângelis); e a Professora Doutora Denise Lino, da UFCG, também integrante da SEJA. Os alunos participantes foram escolhidos aleatoriamente no curso de Comunicação Social da UEPB, independentemente de seus pertencimentos religiosos.

Assim, seguimos esses procedimentos: a) Identificação do tema central das telenovelas e os seus personagens situando-os nos núcleos dramáticos (estes representam determinados estratos sociais, indivíduos e estereótipos); b) Localização e descrição dos diálogos entre os personagens vinculados à temática da espiritualidade, a fim de perceber em cada um a noção de acontecimento narrativo (o que foi dito e como foi dito); c) Observação das ambiências das tramas (cenários, objetos, figurinos, situações espaço-temporais). 


\section{A novela como produto disseminador de pertencimentos}

A trama central de Amor Eterno Amor trata do desejo do reencontro entre seres que se amam e da crença em vidas passadas. Carlos/Rodrigo (Caio Manhente/ Gabriel Braga Nunes) alimenta o sonho de rever seu amor de infância, a menina Elisa (Júlia Gomes). Verbena Borges (Ana Lúcia Torre) não desiste de descobrir o paradeiro de seu filho Rodrigo, desaparecido há quase 30 anos. É esse o fio condutor da trama. A música de abertura é o elemento que produz a fruição poética inicial chamando a atenção dos telespectadores para a novela, "despertando-lhes a atenção para o produto ficcional a ser exibido, pela lógica da familiaridade" (FECHINE; FIGUEIROA, 2009, p. 357). Intitula-se "Leva-me pra Lua", da cantora de MPB Ana Caram, numa versão da canção "Fly Me To The Moon”, de Frank Sinatra. O refrão remete a uma viagem para um lugar paradisíaco, onde se percebe imagens de céu azul, diversas espécies animais e um casal de crianças de mãos dadas, unidos pelo símbolo (um laço) de um amor eterno, a marca da novela.

No capítulo 3, exibido em 07/03/2012, é mostrado que a personagem Clara tem um mau pressentimento em relação à Verbena. A menina, que está na escola, sente o que se passa com a amiga. Em um flash de luz, aparece Verbena com dificuldades de respirar que, sem suportar a dor no peito, desmaia. Clara vê a cena e se desespera. Imagens azuis e brancas se misturam, ilustrando esse acontecimento narrativo, que se torna ainda mais intimista pela música instrumental que ecoa ao fundo. Na cena destacada, identificamos a abordagem da mediunidade infantil, trazendo a ideia de que as crianças são mais propensas a ter visões e pressentimentos, uma vez que sua inocência as impede de fantasiar ou inventar situações. Esse fenômeno é vivenciado pela personagem Clara que, ao longo da trama, visualiza os espíritos e desenha suas imagens. De acordo com o Livro dos Espíritos (KARDEC, 2008), muitas crianças na fase da primeira infância, em razão de uma elevada sensibilidade, manifestam os dons espirituais através de visões ou audições.

Trazendo uma expressiva referência espiritualista desde seu título, a novela $A$ Viagem, de Ivani Ribeiro, pode ser considerada pioneira numa abordagem explicitamente baseada na filosofia de Allan Kardec. Mostrou 
obsessão espiritual, suicídio, reencarnação, temas vistos como tabus pela sociedade da década, predominantemente católica. O plano espiritual mostrado na novela foi inspirado nas descrições da obra Nosso Lar, enviada pelo espírito André Luiz a Chico Xavier. As imagens do Vale dos Suicidas também conferem com o relato apresentado na obra de Pereira (2012). Os demais enfoques são fruto de pesquisa à obra de Kardec, que contém os fundamentos da doutrina: A Gênese, O Céu e o Inferno, O Livro dos Espíritos, O Livro dos Médiuns e o Evangelho Segundo o Espiritismo.

O personagem que conduz a narrativa, uma vez que toda a história se refere a ele, é Alexandre (Guilherme Fontes), um jovem de alto poder aquisitivo, mas que se envolve com o mundo do crime e se suicida na cadeia, após ser condenado por roubo seguido de homicídio. Em espírito, volta à terra para "infernizar" a vida de todos os que julga responsáveis por seu trágico destino. No Além, é encaminhado ao Vale dos Suicidas. Sua revolta aumenta quando, tempos depois, sua irmã Diná (Christiane Torloni) se apaixona por Otávio (Antonio Fagundes), o advogado que o condenou. Adepto do espiritismo e amigo da família, o médico Alberto (Cláudio Cavalcanti) percebe que todos os conflitos são causados por influência do espírito de Alexandre. A trama ganha um novo rumo com a morte de Otávio, que manda sinais de sua presença à amada na Terra. Após um infarto fulminante, ela parte ao seu encontro. Finalmente juntos em outro plano, num lugar denominado Nosso Lar, os dois assumem uma missão comum, que é neutralizar a má influência de Alexandre sobre os que estão na terra. Nas últimas cenas, Diná e Otávio se unem em uma única energia, num dos momentos marcantes da teledramaturgia global: a cena é cercada de luzes e efeitos, ao mesmo tempo em que um texto de cunho espiritualista é lido por um narrador.

As observações dos 160 capítulos da novela $A$ Viagem foram realizadas durante 6 meses. No capítulo 4, Dr. Alberto examina Alexandre, que se encontra deprimido na cadeia onde cumpre sentença. $\mathrm{O}$ rapaz está inconformado com a condenação e diz que, caso morra, irá voltar para se vingar de todos. Acontece o seguinte diálogo: Não é o senhor que é amigo das almas? Pede pros espíritos pra virem aqui dar uma mãozinha pra puxar meu carro! -Dr. Alberto: Não se 
brinca com esse assunto, Alexandre. -Alexandre: Eu tô falando sério. O senhor mesmo falou que quando a gente morre, a gente retorna e vem para outro lugar... Então, quando eu morrer... -Dr. Alberto: A morte é só uma viagem, não é a última! -Alexandre: Se é verdade, anota aí: se eu morrer, eu vou voltar pra me vingar de todo mundo que quis me ferrar... (Uma música de suspense desperta a atenção para o tom de vingança do personagem, ao mesmo tempo em que o médico se entristece, fazendo uma prece em silêncio).

Passemos, neste momento, a Escrito nas Estrelas, observação realizada por meio da internet. A autoria da trama é de Elizabeth Jhin com direção de Pedro Vasconcelos, exibida em 143 capítulos, no período de 12/04/2010 a 24/o9/201o. A música de abertura, Quando a chuva passar, gravada por Paula Fernandes, fala de amor e superação, numa analogia às "tempestades" que os relacionamentos enfrentam vida afora, referindo-se a possibilidade de um amor eterno, semelhante àquele vivido pelos personagens centrais, Ricardo, Viviane e Daniel. Embalados por essa mensagem, os temas espiritualismo, reprodução humana e questões éticas associadas aos avanços da ciência genética se misturam compondo a trama principal. Com a morte do personagem Daniel (Jayme Matarazzo) as visões, premonições e contatos dos demais personagens com o mundo espiritual se tornam frequentes.

No plano espiritual, ele é carinhosamente recebido pelo espírito de sua mãe, Francisca (vivida pela atriz Cássia Kiss); por seu anjo da guarda Seth (Alexandre Rodrigues); e por um espírito de luz, Athael (Carlos Vereza), que orienta seus caminhos. A novela mostra que todos os demais personagens da trama viveram na mesma época e seus destinos se cruzam para o resgate de dívidas antigas e o reforço de laços fraternos. Há também referências à mediunidade infantil, através do personagem Tadeu (Matheus Costa), de 11 anos de idade, que prevê acontecimentos e tem visões. ito! Ao dizer isso, percebe um anjo atrás de Clara, que sorri para ele. No capítulo 22, exibido em 06/05/2010, o menino faz uma excursão com a turma da escola a uma biblioteca. Enquanto a professora Rute apresenta o lugar, ele visualiza anjos andando pelas mesas e outros voando. Ele diz: Quanta gente bonita, de branco, parece até anjos! (Exclama admirado!). -Tia Rute: Que foi Tadeu? Quem é essa 
gente de branco que você está vendo? Onde? Fala para mim! Ele então responde:- Nada não, não tem anjo nenhum aqui! Sai correndo, encontra a amiga Clara, e pergunta a ela: Você acredita em anjo? -Clara: Sim, rezo pro meu anjo da guarda toda noite. -Tadeu: Legal, também acredito.

\section{A visão dos representantes da doutrina espírita}

Após a observação das novelas, a investigação empírica foi o segundo momento do estudo, a fim de verificarmos até que ponto as tramas refletem o Espiritismo. O professor Ivanildo Fernandes Araújo, atuante no Movimento Espírita da cidade desde o ano 2000, entende como positiva a inserção do Espiritismo nas novelas e na mídia de modo amplo: "a divulgação da propagação do conhecimento Espírita pela força da mídia, em âmbito nacional, é algo muito rápido." O problema, na sua opinião, é que novelas e filmes que se dizem de conteúdo espírita trazem alguns misticismos, em relação a alguns aspectos da mediunidade: "da reencarnação, da própria obsessão, criando mitos, fantasias e isso pode afastar as pessoas, pois não correspondem à realidade." Contudo, a influência espiritual mostrada na novela A Viagem, segundo o professor Ivanildo, está doutrinariamente correta. "Retrata muito bem a situação do indivíduo influenciado. Os espíritos desencarnados são atraídos pela nossa forma de pensamento." Perguntado se novelas como essa sugestionam as escolhas religiosas do público, afirmou: "ao assistirmos uma novela, uma produção cinematográfica, somos chamados à reflexão, a mídia induz você a consumir determinados produtos e a religião é uma deles. Então se a novela mostra princípios doutrinários, pode se transformar num grande instrumento de conversão."

Para o professor Oscar de Lira, é normal a introdução de elementos midiáticos que fazem referências à doutrina espírita, tendo em vista a aceitação desse tema no imaginário popular. Nesse sentido, apesar de uma trama da ficção não ter uma bandeira proselitista, a construção do espaço físico, temporal e imagético, somados aos diálogos, corroboram para a divulgação doutrinária. A novela Amor Eterno Amor, de Elizabeth Jhin, colocou ênfase na mediunidade infantil da personagem Clara que, ao longo da trama, estabelece contatos com 
os espíritos denominados por ela de 'amigos de luz'. Para o professor, essa referência permite a popularização da religiosidade espírita, pois, analisando-se a trajetória dos médiuns Chico Xavier e Divaldo Franco, que também eram sensitivos e desde crianças manifestavam suas faculdades mediúnicas, a personagem representa esse princípio espírita. A premonição e a clarividência são evidenciadas na novela, e segundo o professor Oscar, "essas situações podem aproximar as pessoas do espiritismo."

A professora Denise Lino Araújo tem participação no Movimento Espírita desde a infância. Indagada se as novelas permitem a popularização do Espiritismo, argumenta que nenhum grupo social se sente representado na mídia: "a gente só vai se sentir parcialmente representado, porque é um produto de teledramaturgia, que tem múltiplas influências, mas não se pode negar que permite uma grande visibilidade. A mídia é a grande ágora da sociedade moderna”. Comparada com a novela A Viagem, Amor Eterno Amor, segundo a professora, traz discursos do Espiritismo e do catolicismo. "Os personagens sempre falavam em São Miguel Arcanjo, e essa não é uma marca espírita, mas talvez fosse uma forma de atender aos católicos que têm uma simpatia pelo espiritismo.

\section{A percepção da audiência: entrevista com os estudantes de} comunicação da UEPB

Os questionários foram aplicados a 30 estudantes, constituindo uma amostra do tipo não-probabilística intencional, escolhidos conscientemente, por autonomia do pesquisador que já avaliou o campo empírico (RUDIO, 1999). Considerando esses critérios, o roteiro foi composto de 07 perguntas buscando entender quais os reflexos das tramas na percepção da audiência. A primeira questão indagou sobre as novelas a que o entrevistado assistiu. 43\% acompanharam "A Viagem", 37\% "Amor Eterno Amor" e 20\%, "Escrito nas estrelas".

Sobre as razões que levaram os entrevistados a acompanharem as tramas, as respostas variaram. 30 \% responderam que divulgam o espiritismo, $27 \%$ por tratar-se de uma história de amor, $13 \%$ destacaram os efeitos visuais, 
$7 \%$ apontaram o bom roteiro, $7 \%$ se referiram à falta de outra opção e outros $7 \%$, se atraíram pela presença de jovens protagonistas. Para $6 \%$ a mensagem foi o elemento que mais atraiu atenção e $3 \%$ frisaram o interesse por novelas.

O entrevistado João da Rocha dos Santos Neto informou: "o interesse se dá pelo fato da respectiva denominação religiosa ser diferente daquela professada pela maioria dos brasileiros". Quando perguntados acerca das razões que fizeram essas novelas conquistarem uma considerável audiência, $77 \%$ destacaram a temática religiosa ou espírita, enquanto que para $23 \%$, o fato de retratar situações de ficção ou do cotidiano foi suficiente para fomentar seu interesse.

Questionados se as tramas podem despertar a atenção das pessoas para o Espiritismo, 80\% responderam que sim, 13\% talvez, e 07\% acham que não. A discussão proposta por Lopes (2009) explica essa ressonância:“a novela é tão vista quanto falada, pois seus significados resultam tanto da narrativa audiovisual produzida pela televisão quanto da interminável conversação produzida pelas pessoas"(LOPES, 2009, p. 29). Dos que responderam sim, 39\% ressaltaram a boa recepção do Espiritismo, 17\% a influência dos meios de comunicação, 09\% porque as novelas retratam o cotidiano, 08\% notaram abertura para novas formas de religiosidade, $08 \%$ por opção de entretenimento, o8\% por curiosidade, $08 \%$ a atração da temática e $04 \%$ lembraram da inserção de elementos religiosos. Martín-Barbero (2002) elucida que as influências dos meios, sobretudo da TV, não podem ser analisadas somente pelos produtos que divulgam, mas pela dinâmica que envolve seus conteúdos. Na verdade, a cultura é que cria com o campo da comunicação uma teia de relações e implicações.

Dos que responderam talvez, 50\% discorreram sobre a ligação religiosa do telespectador e outros $50 \%$ ponderaram que o desenvolvimento da trama pode ser um possível elemento de interesse.

Para $100 \%$ que afirmaram não, a ligação religiosa adquirida é um fator que impede a abertura à ideologia espírita.

Sobre a identificação com as noções de religiosidade propagadas pelas novelas pesquisadas, $60 \%$ externaram que não, 33\% sim e $07 \%$ talvez. Para 
Mariana de Araujo Castro, "a identidade de uma pessoa, quando se fala de religião, é muito forte e uma simples novela, que dura no máximo 6 meses, não tem o poder de mudá-la”.

Na verdade, a duração é de 8 a 9 meses, e conforme Lopes (2009), é um produto estético e cultural que expressa a identidade do país, "tendo sua história fortemente marcada pela dialética nacionalidade-midiatização. Trata-se de uma narrativa e de um recurso comunicativo que conseguem atuar nas representações culturais" (LOPES, 2009, p. 22).

Para os que responderam sim, sobre a identificação temática, 30\% ressaltaram a reencarnação, $20 \%$ a vida após a morte, outros $20 \%$ o plano espiritual, $20 \%$ a sensibilidade de crianças e animais e $10 \%$ a obra dos médiuns. A entrevistada Shirley Carvalho percebeu essas exposições na novela. "Eu acho que muitas coisas que acompanhamos nas novelas são verdade, como o fato de existirem vidas passadas, mas isso depende muito de crença. Dizem também que crianças e animais são mais sensíveis para esse tipo de coisa e eles acabam vendo mais que adultos, assim foi retratado em 'Escrito nas estrelas', que o cachorro podia ver o dono que já tinha morrido e em 'Amor Eterno Amor'.

A abordagem da religiosidade nas novelas é vista como positiva para $80 \%, 13 \%$ afirmaram que não, enquanto que $07 \%$ relataram que às vezes é interessante a discussão da fé na teledramaturgia.

Dos que responderam que sim, $42 \%$ entendem como uma forma de combater o preconceito, $25 \%$ consideram o debate importante, $21 \%$ relembram a diversidade religiosa no país e $12 \%$ frisam o interesse na doutrina. Para Alidiane Clementino, "deve haver espaço para disseminar as várias religiões, tendo em vista a pluralidade do país". Dos que não concordam com esse enfoque nas novelas, 50\% pontuaram a laicidade do país e os outros 50\% observaram o risco de proselitismo. Em sua última questão, a pesquisa buscou compreender se as novelas analisadas podem influenciar a identidade religiosa das pessoas. Para 50\% sim, 27\% afirmaram que não e $23 \%$ responderam talvez. 
Para os que disseram sim, 40\% defenderam que as novelas influenciam os hábitos, $27 \%$ citaram a falta de engajamento religioso, $20 \%$ se referiram à curiosidade e 13\% à liberdade religiosa. Esses dados corroboram a visão de Hall (2004), quando afirma que a polissemia midiática pode provocar construções identitárias que interferem tanto nos nossos pensamentos, quanto na subjetividade dos nossos pertencimentos sociais.

Para os que disseram não, 62\% declararam-se cristãos, $25 \%$ não percebem o caráter religioso exposto e 13\% ignoram a temática. Para os que afirmaram talvez, 66\% alertaram para o discurso midiático, 20\% destacaram que não possuíam religião e para os outros $14 \%$, depende da religião que o receptor segue.

\section{Conclusões}

Mousinho (2012) assinala que as novelas funcionam como veículos de intertextualidade e matrizes de circulação cultural, uma vez que utilizam o dialogismo como caminho gerador para novas práticas discursivas. Assim, a pesquisa mostrou que existe um sutil processo de disseminação e encaminhamento de temas, conceitos, costumes, tradições que refletem as expressões de religiosidade do povo brasileiro. Desse modo, as novelas são pensadas e tecidas para produzir diferentes leituras, influências e visões sobre a audiência, "propondo um novo olhar capaz de reativar sentidos, ampliar a percepção, através do esforço das narrativas e dos personagens" (MOUSINHO, 2012, p. 148).

Aquelas que abordam temas espiritualistas são recorrentes e fazem grande sucesso junto ao público, numa relação que Martino (2003) acredita ser fruto da identificação e da projeção coletivas, que geram uma ressonância significativa no espaço social. De acordo com tal perspectiva, a identificação produz-se quando o público assume emotivamente o ponto de vista da ficção ao considerá-lo um reflexo de seus sonhos e ideais. Desse modo, as novelas (lugares de cenas de massas, conforme diz Martín-Barbero) geram também novas demandas narrativas e discursivas quando tratam de temáticas espiritualistas, funcionando como um eficiente canal de circulação de bens 
simbólicos religiosos (MARTINO, 2003, p.14). Esses bens repercutem na sociedade e desencadeiam a empatia dos telespectadores, que são seduzidos a cada dia pelas tramas e imagens. Para Martín-Barbero (2002), o gênero telenovela mistura em suas narrativas a emoção, a comédia, o fantástico, a aventura, reproduzindo uma marca inerente ao contexto ficcional das tramas latino-americanas.

As narrativas analisadas ainda apontaram um fato que merece destaque: as novelas de Elizabeth Jhin, Amor Eterno Amor e Escrito nas Estrelas, exibidas às 18 horas, trazem em comum regularidades indicativas e demarcadoras de abordagens espiritualistas, provocando o reconhecimento autoral por parte do público. Ou seja, quem assistiu a Escrito nas Estrelas já sabe o que pode esperar do roteiro de Amor Eterno Amor. Trata-se de uma marca de distinção autoral e de similaridade temática, afinal o ato criador é associado a estilos próprios (SOUZA; OROFINO: RIGHINI, 2009). Os pesquisadores salientam ainda que quanto mais se conhece as práticas de produção e apreciação das telenovelas, maiores condições existem para identificar não apenas esses estilos, como também as maneiras de exposição dos afetos, da linguagem utilizada, dos dramas amorosos e familiares. Isso nos parece verdadeiro, pois quando nos reportamos a Amor Eterno Amor e Escrito nas Estrelas, localizamos enfoques sobre vidas passadas e reencarnação.

A novela A Viagem, criação autoral de Ivani Ribeiro, articula-se com os princípios da doutrina espírita, agregando à novela um caráter de verossimilhança e intertextualidade, intercalando ficção e realidade, à medida que busca retratar o universo religioso referente ao contexto da fé Kardecista. Os sentidos analisados, resultantes de processos de criação ficcional, apontam, nas situações e diálogos uma possível proximidade com alguns princípios da literatura espírita, descontando-se, evidentemente, os recursos de livre adaptação adotados pelas autoras Elizabeth Jhin e Ivani Ribeiro: as "licenças poéticas" que legitimam e potencializam as fantasias da ficção. Todavia, os conteúdos apresentados, segundo os especialistas, requerem estudo e aprofundamento, uma vez que surgem romanceados nas tramas. 
Assim, o tema estudado permitiu facetas instigantes para a compreensão da interface entre campo religioso e campo da comunicação, especialmente no que concerne aos modos de endereçamento da ficção e as estratégias ali mobilizadas, além de ter recebido significativa acolhida nos congressos, a exemplo do INTERCOM 2013 (no GP Ficção Seriada), evento que reúne especialistas e pesquisadores do campo da comunicação. Por isso, a lógica ficcional continua instigando nossa compreensão, capítulo a capítulo, sinalizando que as relações da religiosidade com as produções televisivas exigem de nós significativo esforço de interpretação, escapando a quaisquer análises redutoras. As leituras e os resultados alcançados, além de serem socializados nos eventos, têm suscitado novos questionamentos acerca das relações entre comunicação e religiosidade, pelo viés da ficção, inspirando estudos futuros, a serem propostos para a iniciação científica da UEPB. Sinal de que a ciência, como a vida, está sujeita a intensos desdobramentos e curiosidades próprias do não saber que configura a incompletude humana e justifica o prazer de se fazer pesquisa.

\section{Referências}

DUARTE, Jorge. Entrevista em profundidade. In: DUARTE, Jorge; BARROS, Antonio (Orgs). Métodos e técnicas de pesquisa em comunicação. São Paulo: Atlas, 2005.

FAUSTO NETO, Antonio. Midiatização e processos sociais na América Latina. São Paulo: Paulus, 2008.

FECHINE, Yvana; FIGUEIROA, Alexandre. Produção ficcional brasileira no ambiente de convergência: experiências sinalizadoras a partir do Núcleo Guel Arraes. IN: LOPES, Maria Immacolata Vassalo de (org). Ficção televisiva no Brasil: temas e perspectivas. São Paulo: Globo, 2009.

HALL, Stuart. A identidade cultural na pós-modernidade. Rio de Janeiro: DP\&A, 2004.

KARDEC, Allan. O livro dos espíritos: princípios da doutrina espírita. São Paulo, FEB/Lake, 2008.

LOPES, Maria Immacolata Vassalo de. Telenovela como recurso comunicativo. Revista Matrizes. Ano $3^{-} \mathrm{N}^{0}$ 1- $^{-}$São Paulo: ECA/USP/PAULUS, Agosto/Dezembro, 2009.

MARTÍN-BARBERO, Jésus. Dos meios às mediações. Rio de Janeiro: Editora UFRJ, 2002. 
MARTINO, Luís Mauro. Mídia e poder simbólico: um ensaio sobre comunicação e campo religioso. São Paulo: Paulus, 2003.

MOTTA, Luiz Gonzaga. Análise pragmática da narrativa jornalística. In: LAGO, Cláudia; BENETTI, Marcia (Orgs). Metodologia de pesquisa em jornalismo. Petrópolis: Vozes, 2007.

MOUSINHO, Luiz Antonio. A sombra que me move: ensaios sobre ficção e produção de sentido (cinema, literatura, TV). João Pessoa: Ideia, 2012.

PAIVA, Claúdio Cardoso. Dionísio na Idade Mídia: estética e sociedade na ficção televisiva seriada. João Pessoa: Editora da UFPB, 2010.

PEREIRA, Yvonne A. Memórias de um suicida. $27^{\mathrm{a}}$ ed. Rio de Janeiro: FEB, 2012.

RUDIO, Franz Victor. Introdução ao projeto de pesquisa. Petrópolis: Vozes, 1999.

SANTAELlA, Lucia. Comunicação e pesquisa. São Paulo: Hacker Editores, 2001.

SODRÉ, Muniz. A narração do fato: notas para uma teoria do acontecimento. Petrópolis: Vozes, 2008.

SOUZA, Maria Carmem Jacob; OROFINO, Isabel; RIGHINI, Rafael Roso. Criadores na dramatização da juventude, do feminino e da pobreza. IN: LOPES, Maria Immacolata Vassalo de (org). Ficção televisiva no Brasil: temas e perspectivas. São Paulo: Globo, 2009. 